\title{
The discrimination of bimodal temporal gaps
}

\author{
ROBERT ROUSSEAU \\ and \\ ALFRED B. KRISTOFFERSON \\ McMaster University, Hamilton, Ontario, Canada
}

Difference thresholds for the duration of empty time intervals marked off by a light flash and a tone burst were determined at base durations extending from 100 to 2000 msec. Threshold is shown not to be a function of base duration. For base durations in the lower part of the range studied, threshold is much higher than that usually obtained in experiments done under other conditions.

Many experiments have shown that the differential threshold for duration is a monotonic increasing function of base duration. If the discrimination is between a stimulus of duration $t$ (the base duration) and one of duration $t+\Delta t$, the value of $\Delta t$ required for $75 \%$ correct responses, $\Delta \bar{t}$, becomes larger as $t$ is increased. Most of the evidence for this conclusion comes from experiments in which auditory signals have been used to define the durations (Stott, 1933; Blakely, 1933; Henry, 1948; Creelman, 1962; Small \& Campbell, 1962; Treisman, 1963; Abel, 1972a, b).

One study using cutaneous signals yielded results in general agreement with the auditory studies (Hawkes \& Warm, 1961). However, a recent paper on duration discrimination of light flashes concluded that $\Delta \bar{t}$ is independent of base duration, at least over the narrow range of $50-150 \mathrm{msec}$ which they investigated (Allan, Kristofferson, \& Wiens, 1971).

In experiments such as these, it is often possible to use cues other than duration. This is especially true with brief durations. The dependence of dimensions such as loudness and brightness upon stimulus duration is well known. Allan et al (1971) provided some evidence to show that luminance-related cues were not influential in their experiments, and Abel (1972a, b) has argued that the use of empty intervals defined by the offset of a first signal and the onset of a second signal reduces the magnitude of the problem. However, there still are uncertainties in this regard in most, if not all, previous studies.

We have chosen to investigate duration discrimination using bimodal empty intervals to reduce further the possibility that interactions between the sensory effects of the "markers" can be a source of information to the S. Our time intervals were defined by the offset of a light, followed after the required time by the onset of a tone. The results are striking: An increase in base duration from 100 to $2000 \mathrm{msec}$ produced no significant changes in $\Delta \bar{t}$.

Each time interval was presented as the time between the offset of a 500-msec spot of light and the onset of a $500-\mathrm{msec} 2-\mathrm{kHz}$ pure tone. Both markers were readily detectable. On each trial, the $S$ was presented a single interval which he had to identify as either "short" or "long." There were two possible intervals within a session, one of duration $t$ and the other $t+\Delta t$. They were presented equally often in random order. Following his response on each trial, the stimulus was identified for the $\mathrm{S}$ by a feedback signal.

Psychometric functions were obtained at four base durations $(100,600,1200$, and $2000 \mathrm{msec})$. Each $S$ received between 2000 and 3000 trials of practice with a fixed value of $\Delta t$ and then ran through 10 experimental sessions of 280 trials each. These 10 sessions consisted of two successive random sequences of five values of $\Delta t$, only one $\Delta t$ being presented during a session. Each $S$ was used for one base duration only. A total of 21 Ss was tested.

The probability of a correct response, $\mathrm{P}(\mathrm{C})$, was calculated for each $\Delta t$ for each $S$, and a value of $\Delta \bar{t}$ for $P(C)=.75$ was determined by linear interpolation. The value of $\Delta \bar{t}$ for each $S$ is given in Table 1 .

Individual differences are large, but the conclusion that base duration is without effect seems quite clear. On the average thresholds are high, the Weber ratio varying from 1.64 at $t=100$ to .08 at $t=2000$. Comparing these to results obtained in auditory studies (see, e.g., Fig. 12 in Creelman, 1962) suggests that performance is similar for base durations over about $1000 \mathrm{msec}$ but that reducing base duration produces no improvement in performance in the present bimodal case.

We have also analyzed these data by calculating the equal-variance $\mathrm{d}^{\prime}$ for each $\Delta t$ for each $\mathrm{S}$. The individual $\mathrm{d}^{\prime}$ vs $\Delta \mathrm{t}$ functions appear to be linear, with zero intercepts. The mean of the slopes of the individual functions is 0.0086 , and the slopes are not significantly affected by base duration.

Table 1

Values of $\Delta t$ (in Milliseconds) Yielding $75 \%$ Correct Responses for 21 Observers and Four Base Durations

\begin{tabular}{lrrrr}
\hline & \multicolumn{4}{c}{ Base } \\
& 100 & 600 & 1200 & 2000 \\
\hline & 143 & 84 & 132 & 156 \\
& 243 & 176 & 137 & 107 \\
& 113 & 138 & 154 & 267 \\
& 157 & 177 & 226 & 134 \\
& & 277 & 270 & 151 \\
Mean & 164 & 125 & 111 & \\
SD & 56 & 163 & 171 & 163 \\
& & 66 & 62 & 61 \\
\hline
\end{tabular}


There may be several mechanisms that can be used to "take a measure" of stimulus duration. It is possible that one such mechanism is used for long durations and that, as base duration is shortened, other more efficient mechanisms become available, accounting for the decline in threshold observed in most studies. It may be that, under the conditions of the present experiment, those "more efficient" mechanisms are not or cannot be utilized.

Were our Ss unable to use them because we used bimodal signals? We doubt that that is the case because we have additional bimodal data, reported elsewhere (Kristofferson \& Allan, 1973), which shows substantially better performance than that reported in this paper. The performance is not as good as it is in most unimodal experiments, however. And we do not know whether it is a function of base duration-although it must be. Only one base duration was used in that experiment. The only difference between the two experiments is that the signal pulses were both $500 \mathrm{msec}$ in the present experiment and they were both $10 \mathrm{msec}$ in the earlier experiment. Finally, we have done one other experiment identical to the present one, except that only the $100-\mathrm{msec}$ base duration was used. The duration of the first marker, the light, was varied in three steps of 10 , 500 , and $4000 \mathrm{msec}$. This manipulation had no effect; performance was the same as in the present experiment. We do not know yet what the controlling variables are.

We do conclude, however, that there are conditions under which duration discrimination performance is not affected by base duration, even for brief durations. This experiment is one case and the Allan et al (1972) experiments are another. Theories based upon the data in the auditory literature are likely to have limited generality.

\section{REFERENCES}

Abel, S. M. Duration discrimination of noise and tone bursts. Journal of the Acoustical Society of America, 1972a, 51, 1219-1223.

Abel, S. M. Discrimination of temporal gaps. Journal of the Acoustical Society of America, $1972 \mathrm{~b}, 52,519-524$.

Allan, L. G., Kristofferson, A. B., \& Wiens, E. W. Duration discrimination of brief light flashes. Perception \& Psychophysics, 1971, 9, 327-334.

Blakely, W. A. The discrimination of short empty intervals. PhD dissertation, University of Illinois, 1933.

Creelman, C. D. Human discrimination of auditory duration. Journal of the Acoustical Society of America, 1962, 34, 582-593.

Hawkes, G. R., \& Warm, J. S. $\Delta \mathbf{T}$ for electrical cutaneous stimulation. Journal of Psychology, 1961, 51, 263-271.

Henry, F. M. Discrimination of the duration of a sound. Journal of Experimental Psychology, 1948, 38, 734-743.

Kristofferson, A. B., \& Allan, L. G. Successiveness and duration discrimination. In $S$. Kornblum (Ed.), Attention and performance IV. New York: Academic Press, 1973.

Small, A. M., \& Campbell, R. A. Temporal differential sensitivity for auditory stimuli. American Journal of Psychology, 1962, 75, 401-410.

Stott, L. H. The discrimination of short tonal durations. PhD dissertation, University of Illinois, 1933.

Treisman, M. Temporal discrimination and the indifference interval. Psychological Monographs, 1963, 77, No. 13(Whole No. 576).

(Received for publication November 28, 1972.) 